\title{
Optimization of Vibration Reduction Ability of Ladder Tracks by FEM Coupled with ACO
}

\author{
Hao Jin, ${ }^{1}$ Weining Liu, ${ }^{2}$ and Shunhua Zhou ${ }^{1}$ \\ ${ }^{1}$ Key Laboratory of Road and Traffic Engineering of Ministry of Education, Tongji University, Shanghai 201804, China \\ ${ }^{2}$ School of Civil Engineering, Beijing Jiaotong University, Beijing 100044, China \\ Correspondence should be addressed to Hao Jin; zhujijinhao@gmail.com
}

Received 28 March 2015; Revised 25 May 2015; Accepted 10 June 2015

Academic Editor: Georges Kouroussis

Copyright (c) 2015 Hao Jin et al. This is an open access article distributed under the Creative Commons Attribution License, which permits unrestricted use, distribution, and reproduction in any medium, provided the original work is properly cited.

\begin{abstract}
Ladder track, which has drawn increased attention in scientific communities, is an effective method for reducing vibrations from underground railways. In order to optimize the vibration reduction ability of ladder track, a new method, that is, the finite element method (FEM) coupled with ant colony optimization (ACO), has been proposed in this paper. We describe how to build the FEM model verified by the vibration tests in the Track Vibration Abatement and Control Laboratory and how to couple the FEM with ACO. The density and elasticity modulus of the sleeper pad are optimized using this method. After optimization, the vibration acceleration level of the supporting platform in the $1-200 \mathrm{~Hz}$ range was reduced from $102.8 \mathrm{~dB}$ to $94.4 \mathrm{~dB}$. The optimized density of the sleeper pad is $620 \mathrm{~kg} / \mathrm{m}^{3}$, and the optimized elasticity modulus of the sleeper pad is $6.25 \times 10^{6} \mathrm{~N} / \mathrm{m}^{2}$.
\end{abstract}

\section{Introduction}

Vibrations generated by underground railways are one of the most serious engineering problems of such systems. Waves induced by the dynamic interaction between the train wheels and the rails propagate from the surrounding soils to the foundations of nearby buildings [1], resulting in structural vibrations and reradiated noise. One effective method for reducing vibrations from underground railways is to use ladder tracks.

The idea for ladder track was originally from the baulk road system and was then applied in the Leeds and Selby Railway in 1830. From the middle of the 20th century, systematic research on ladder track was started in Japan, Russia, and France. In the last 10 years, the vibration reduction performance of ladder track by the Railway Technical Research Institute of Japan has attracted great attention from Asian researchers, especially in China.

In the early 1990s, Wakui et al. [2] reported its new development in Japan. Oyado et al. [3] analyzed running performance and dynamic settlement test results of a ballasted ladder track. Initially, the ladder track was usually used as a ballasted track. Hosking and Milinazzo [4] built a simple mathematical model to study ladder track responses under steadily moving loads by employing the periodic discrete elastic support of the combined floating rails. This model was extended to include the support mass and viscous damping [5]. Hui and $\mathrm{Ng}$ [6] measured the vibration velocity level at the station using the ladder track. The results showed that the ladder track has better mitigation properties above $35 \mathrm{~Hz}$, compared with ballast track. The first bending resonance of ladder track is $31.5 \mathrm{~Hz}$ under a moving train load. In the Beijing subway system, Xia et al. [7-9] and Inoue et al. [10] compared the dynamic response of an elevated bridge having ordinary nonballasted slab track with a bridge having ladder track. Theoretical analysis and experimental study proved that the ladder track has good vibration reduction characteristics. Jin et al. performed a modal analysis of the ladder track with different bearing forms by a numerical method [11] and a laboratory test [12]. The results showed that the first natural frequency of ladder track occurs at $33-36 \mathrm{~Hz}$. To solve the problem of rail corrugation, the dynamic properties of the ladder track used in the Beijing subway were optimized by Yan et al. $[13,14]$.

The present contribution aims to optimize vibration reduction ability of ladder track by FEM coupled with ACO. This paper is organized as follows. Section 2 describes a vibration test of ladder track performed in the Track Vibration Abatement and Control Laboratory. In Section 3, 
TABLE 1: Properties of the ladder track.

\begin{tabular}{lccc}
\hline Part & Density $\left(\mathrm{kg} / \mathrm{m}^{3}\right)$ & Elasticity modulus $\left(\mathrm{N} / \mathrm{m}^{2}\right)$ & Poisson's ratio \\
\hline Rail & $7.85 \times 10^{3}$ & $2.14 \times 10^{11}$ & 0.3 \\
Longitudinal sleeper & $2 \times 10^{3}$ & $5 \times 10^{10}$ & 0.167 \\
Supporting platform & $2.6 \times 10^{3}$ & $3.6 \times 10^{10}$ & 0.167 \\
Connecting beam & $7.85 \times 10^{3}$ & $2.14 \times 10^{10}$ & 0.3 \\
\hline
\end{tabular}

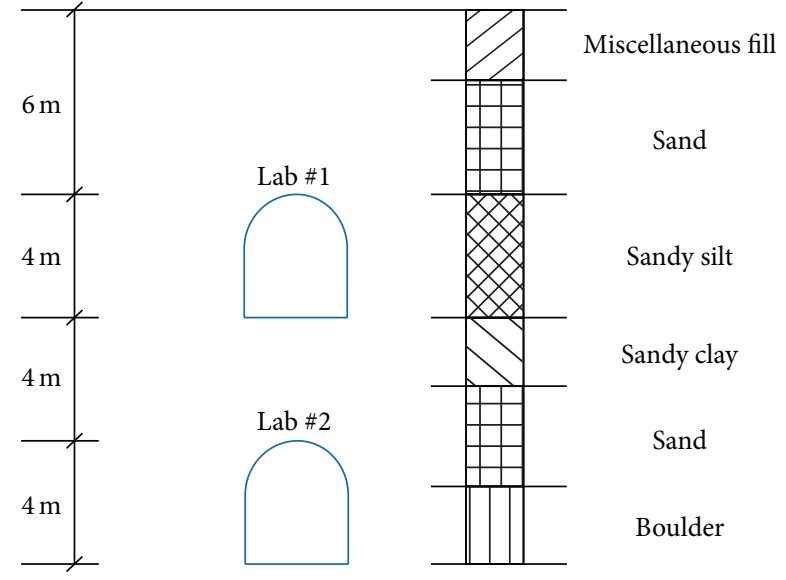

FIGURE 1: Section plan of the laboratory.

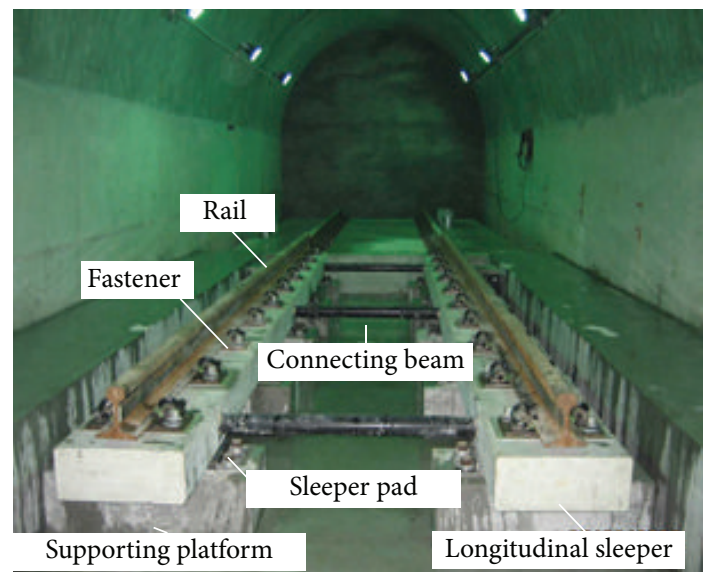

FIgURE 2: Ladder track located in Lab \#2. a description is given of an FEM model that was built using the commercial software LS-DYNA and verified based on the tested ladder track. Then, the FEM model coupled with ACO is introduced in Section 4. In Section 5, the optimization of the vibration reduction performance of ladder track is explained. Conclusions are given in Section 6.

\section{Vibration Testing in the Laboratory}

The Track Vibration Abatement and Control Laboratory of Beijing Jiaotong University is a two-story underground structure for researching track vibration and is the only such facility in Asia. The buried depth of Lab \#1 is $6 \mathrm{~m}$, and the buried depth of Lab \#2 is $14 \mathrm{~m}$. Figure 1 shows the ground conditions around the laboratory.

One unit of ladder track was constructed in Lab \#2 (Figure 2). The cross section of Lab \#2 is in the shape of a horseshoe. The height is $4 \mathrm{~m}$, and the width is $4 \mathrm{~m}$.

The test track used $60 \mathrm{~kg} / \mathrm{m}$ rail, which was $6.15 \mathrm{~m}$ in length. Ten WJ-2 fasteners were employed to fix each rail in place. The size of the longitudinal sleeper was $6.15 \mathrm{~m} \times$ $0.46 \mathrm{~m} \times 0.185 \mathrm{~m}$. The size of the connecting beam, which was designed to connect the two longitudinal sleepers, was $0.975 \mathrm{~m} \times 0.06 \mathrm{~m} \times 0.06 \mathrm{~m}$. There were five sleeper pads under each longitudinal sleeper. The size of the sleeper pad was $0.46 \mathrm{~m} \times 0.25 \mathrm{~m} \times 0.03 \mathrm{~m}$. The size of the supporting platform was $0.86 \mathrm{~m} \times 0.4 \mathrm{~m} \times 0.28 \mathrm{~m}$. Ten supporting platforms were used for the test ladder track. Figure 3 shows the plan of the test ladder track. Figure 4 illustrates the cross section of the test ladder track.
As the vibration source, an automatic falling weight machine, shown in Figure 5, was designed and was employed to provide impulse to the rail. By changing the number of mass blocks and the drop height, different impulse forces could be obtained. The material of the hammer head could also be changed to aluminum, rubber, nylon, or steel. To avoid influencing the sleeper by the mass of the setup, a scaffold was installed to support the automatic falling weight machine.

For this test, five mass blocks, $73 \mathrm{~kg}$ in total, were installed. The aluminum hammer head was used and the drop height was $10 \mathrm{~cm}$. A force sensor was installed in the hammer head. The impulse site is the middle of one rail (see Figure 3 ). The sampling frequency of the force signal was $12.8 \mathrm{kHz}$. The time history of the average impulse force, with a peak value of $55 \mathrm{kN}$, is shown in Figure 6. The vibration acceleration sensor was fixed on the middle supporting platform to measure the vertical vibration, as shown in Figure 3. The sampling frequency of the acceleration signal was $1600 \mathrm{~Hz}$.

\section{FEM Model Building and Verification}

3.1. Building the FEM Model. The commercial software LSDYNA was employed to build the FEM model of the test ladder track. The geometry of the longitudinal sleepers, the connecting beams, and the supporting platforms are described in Section 2. Considering the calculation time of the LS-DYNA software, the cross section of the rail was simplified, as demonstrated in Figure 7.

The properties of the rails, the longitudinal sleepers, the supporting platforms, and the connecting beams are presented in Table 1. 


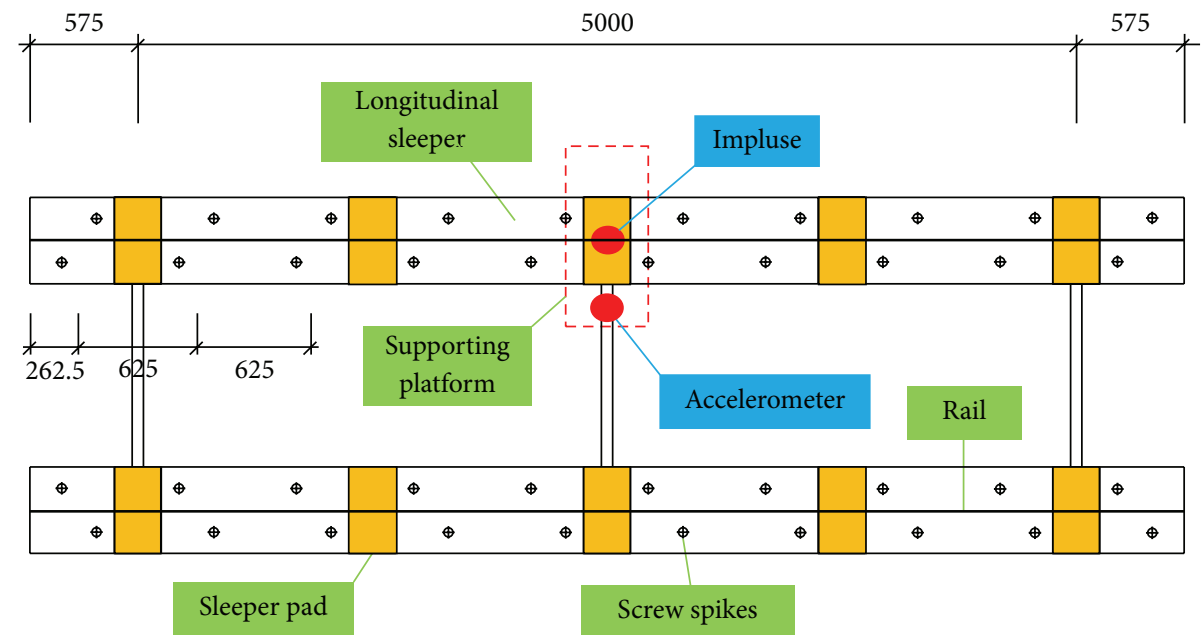

FIgURE 3: Plan of the test ladder track (unit: $\mathrm{mm}$ ).

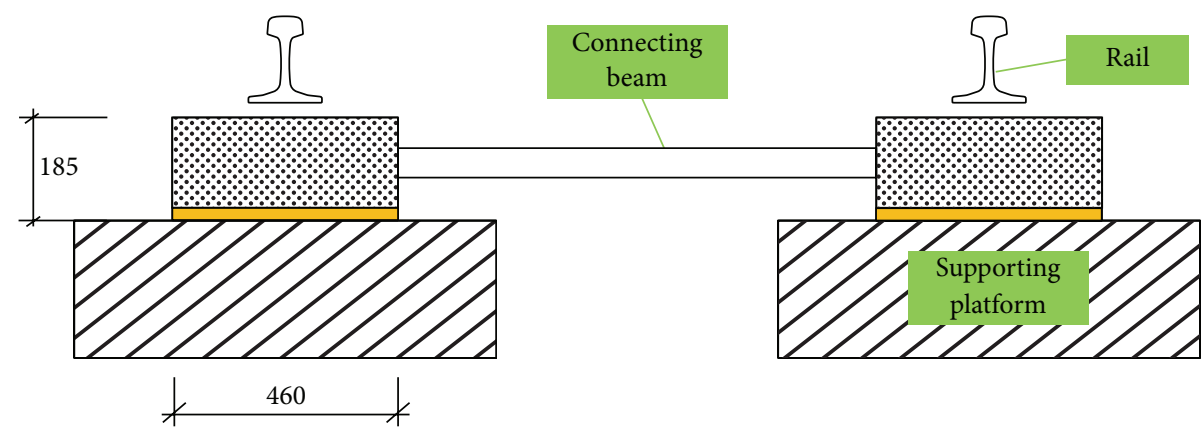

Figure 4: Cross section of the test ladder track (unit: $\mathrm{mm}$ ).

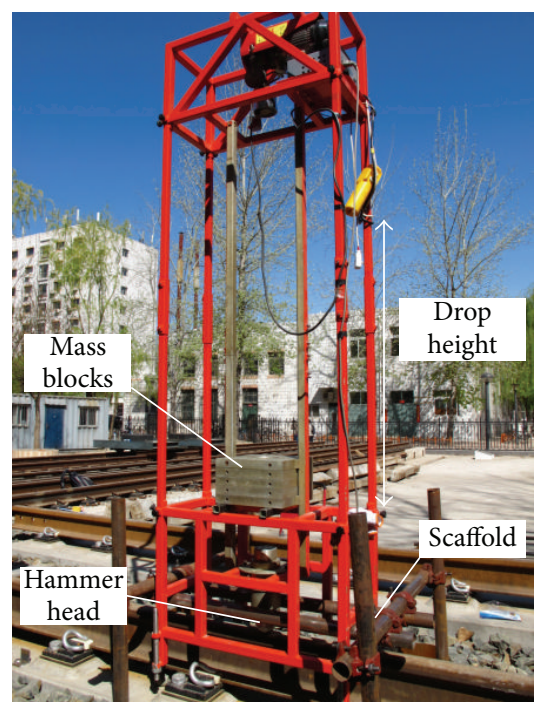

FIGURE 5: Automatic falling weight machine.

Springs were used to simulate the fasteners and the sleeper pads. The vertical stiffness of the fastener was $60 \mathrm{MN} / \mathrm{m}$. The vertical stiffness of the sleeper pad was $18.055 \mathrm{MN} / \mathrm{m}$. Figure 8 shows the FEM model established

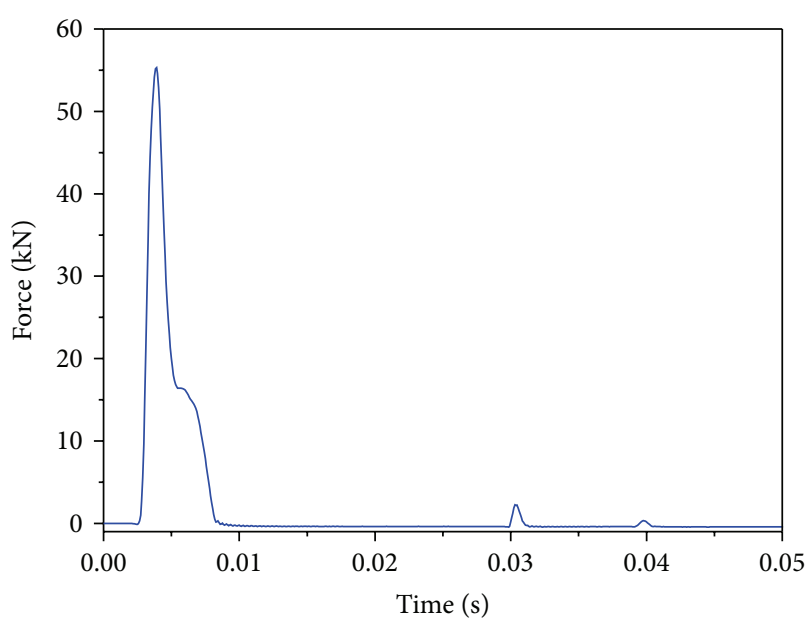

FIGURE 6: Time history of the average impulse force.

by LS-DYNA. The bottom of all supporting platforms was constrained in all directions.

3.2. FEM Model Verification. The impulse force shown in Figure 6, which was obtained from laboratory testing, was 


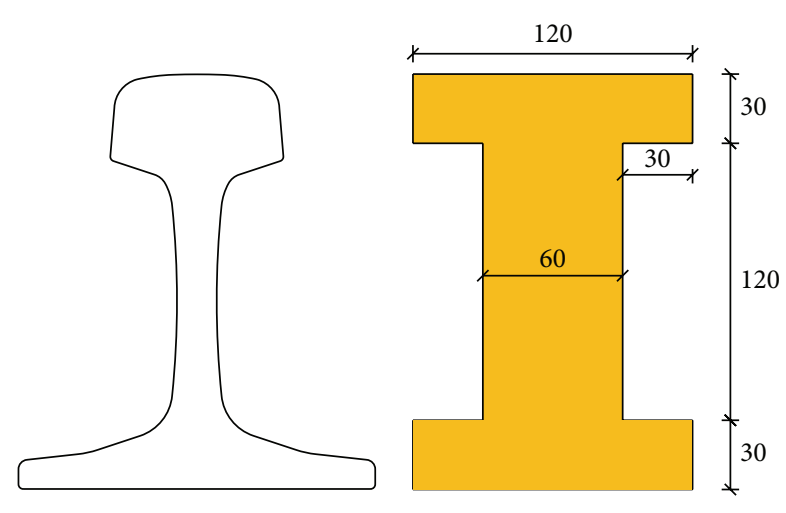

FIGURE 7: Simplified cross section of the rail (unit: mm).

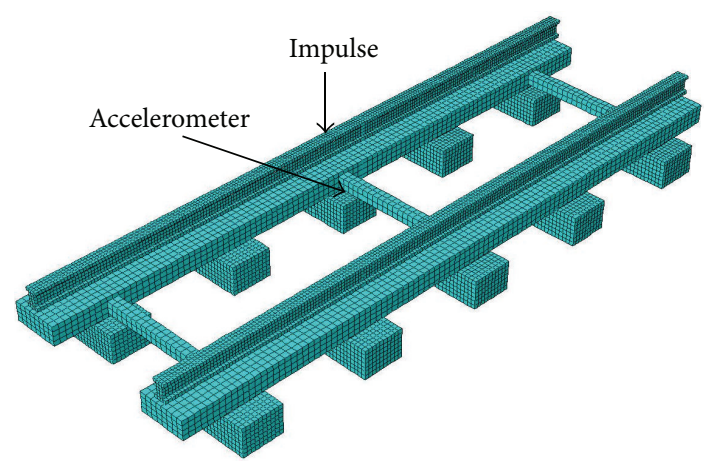

FIGURE 8: FEM model established by LS-DYNA.

used in the FEM model. Then, the vibration acceleration of the middle supporting platform was calculated. Figure 9 shows the calculated result and the test result. From Figure 9, we see that the calculated and the test results are almost the same. Therefore, the FEM model is accurate for the following calculation in Section 4.

\section{FEM Coupled with ACO}

4.1. Ant Colony Algorithm. With the development of computer technology, swarm intelligence optimization algorithms, including ant colony optimization (ACO) and particle swarm optimization (PSO), have attracted increased attention. ACO is one of the most successful swarm intelligence optimization algorithms. It was proposed by Colorni et al. [15] to solve the traveling salesman problem in 1991. It was named the ant system (AS), inspired by the foraging behavior of the Argentine ants [16-18]. In recent years, ACO has been used to successfully solve many combinatorial optimization problems $[19,20]$ and is being extended to obtain the solutions of continuous problems [21]. There are many different ACOs based on the AS. In this paper, Chen's ACO [22] was employed to solve the continuous function. Here is a function of one variable describing Chen's ACO.

$f(x)$ is the original objective function, and $x$ is the original design variable whose minimum (maximum) value is $a(b)$. Let $f(x)$ be $f\left(x^{\prime}\right)$ by simple mathematical transform, in which $x^{\prime}=(x-a) /(b-a), x^{\prime} \in(0,1)$.

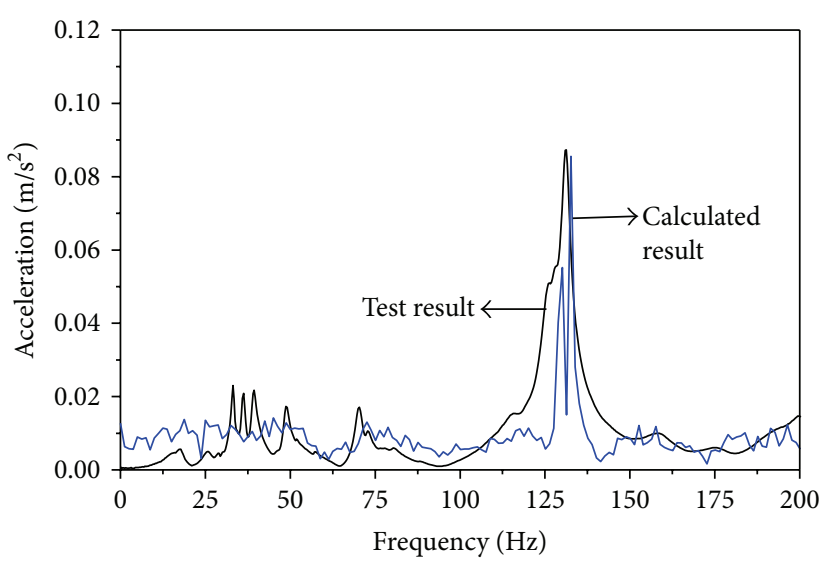

FIgURE 9: Time history of the vibration acceleration of the middle supporting platform.

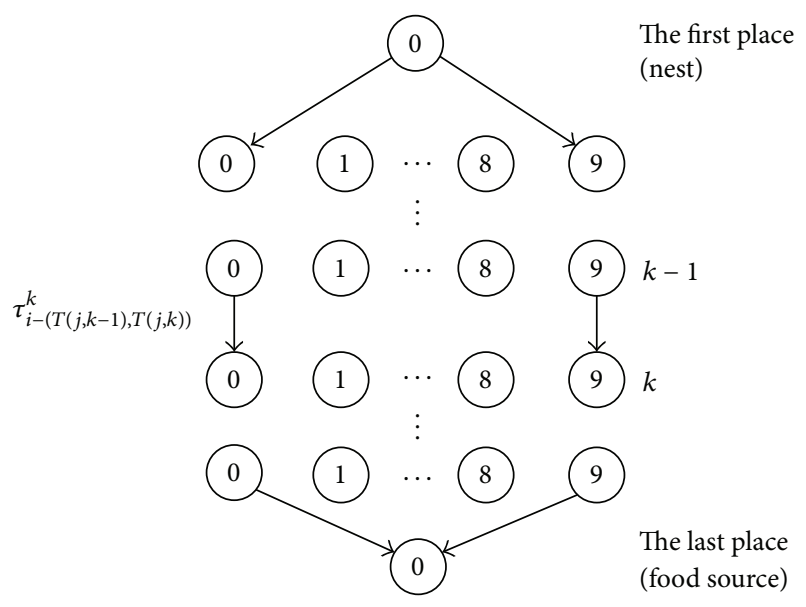

FIgURE 10: Decimal digit string.

Therefore, the optimization process for function $f\left(x^{\prime}\right)$ is simplified to an artificial ant that makes a selection from ten decimal numbers whenever it takes a step, except for the first place and the last place (see Figure 10).

Each artificial ant goes from the first floor (the nest) toward the last floor (the food source). $T(j, k-1)$ is the decimal number when ant $j$ is at floor $(k-1)$. Ant $j$ selects the decimal number of the next floor according to

$$
T(j, k)= \begin{cases}\max \left\{\tau_{i-(T(j, k-1), T(j, k))}^{k}\right\}, & q<Q_{0} \\ \text { randperm, } & q \geq Q_{0}\end{cases}
$$

in which $q$ is a real random variable uniformly distributed in the internal array $[0,1], Q_{0}$ is a tunable parameter controlling the influence of the pheromone, randperm is a number randomly selected from $(0,1, \ldots, 9)$, and $\tau_{i-(T(j, k-1), T(j, k))}^{k}$ is the pheromone intensity laid on the path between the number $T(j, k-1)$ to $T(j, k)$.

When an ant finishes one step, that is, an ant arrives at floor $k$ from floor $(k-1)$, the strength of the pheromone $\tau_{i-(T(j, k-1), T(j, k))}^{k-1}$ laid on the path between the number 


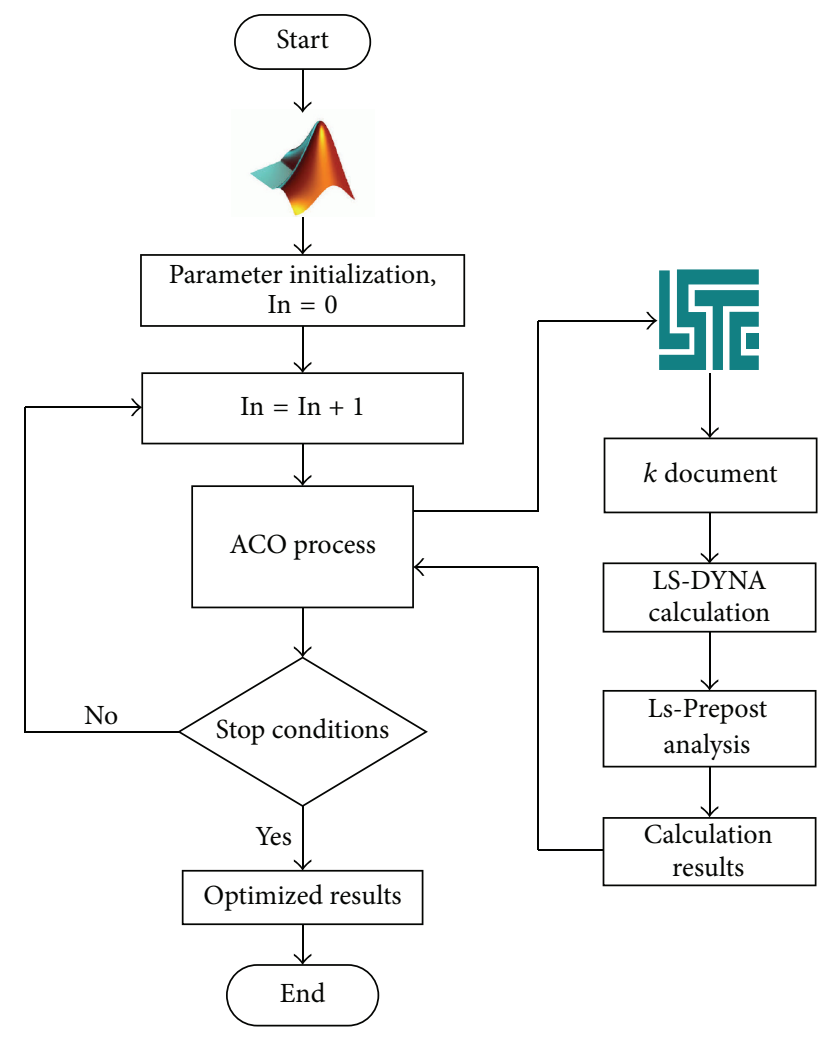

FIgURE 11: Program flow of FEM coupled with ACO.

$T(j, k-1)$ and the number $T(j, k)$ by ant $j$ should be updated as follows:

$$
\tau_{i-(T(j, k-1), T(j, k))}^{k-1} \longleftarrow(1-\rho) \tau_{i-(T(j, k-1), T(j, k))}^{k-1}+\alpha,
$$

where $\alpha$ is the modified coefficient of the pheromone intensity and $\rho$ is the local evaporation factor of the pheromone.

After all the ants have arrived at the last place, the best solution for a given interior can be obtained. Through all interiors, the best solution of the function can be obtained.

According to the function tests, Chen's ACO parameters are $\alpha=\rho=0.3, Q_{0}=0.55$. The interior number In is 10 , and the ant number An is 10 .

4.2. FEM Coupled with ACO. The calculation code for Chen's ACO was written in Matlab. The FEM model was carried out through the DOS functions in Matlab. The detailed program flow is demonstrated in Figure 11.

\section{Optimization}

5.1. Optimization Objective. Vibrations induced by the interaction between the wheels and the rails are transferred from the rails to the invert and then propagate to the foundations of nearby buildings, resulting in structure vibrations and reradiated noise. Therefore, the vibration of the supporting platform reflects the structure vibration. To reduce the structure vibration, the platform vibration should first be

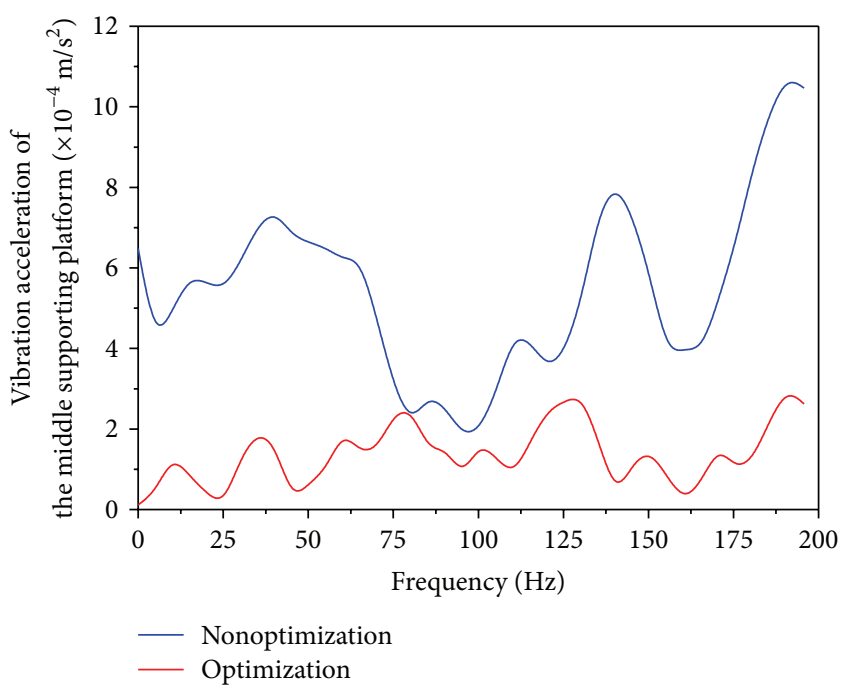

FIGURE 12: Vibration acceleration comparison between nonoptimization and optimization.

reduced. Consequently, platform vibration acceleration was set as the optimization objective. The objective function was

$$
\min V_{a} L_{m}=20 \times \log \frac{\sqrt{(1 / N) \times \sum_{i=1}^{N} a_{i-\mathrm{rms}}^{2}}}{a_{0}},
$$

where $V_{a} L_{m}$ is the vibration acceleration level of the supporting platform, $N$ is the tested number ranging from $1 \mathrm{~Hz}$ to $200 \mathrm{~Hz}, a_{i \text {-rms }}^{2}$ is the effective value of the vibration acceleration at the frequency point, and $a_{0}=1 \times 10^{-6} \mathrm{~m} / \mathrm{s}^{2}$ is the reference value of the vibration acceleration.

5.2. Optimization Variables. In engineering, the density and the elasticity modulus of the sleeper pad are always modified for the optimizing reduction in vibrations. Consequently, the density of the sleeper pad and the elasticity modulus of the sleeper pad were set as the optimization variables. In practical applications, the density of the sleeper pad ranges from $500 \mathrm{~kg} / \mathrm{m}^{3}$ to $1500 \mathrm{~kg} / \mathrm{m}^{3}$. The elasticity modulus of the sleeper pad varies from $2.6 \times 10^{6} \mathrm{~N} / \mathrm{m}^{2}$ to $7.8 \times 10^{6} \mathrm{~N} / \mathrm{m}^{2}$.

5.3. Optimization Results. The optimization results were obtained by the program presented in Section 4 . The optimized density of the sleeper pad is $620 \mathrm{~kg} / \mathrm{m}^{3}$ and the optimized elasticity modulus of the sleeper pad is $6.25 \times 10^{6} \mathrm{~N} / \mathrm{m}^{2}$. Before optimization, the vibration acceleration level of the middle supporting platform, ranging from $1 \mathrm{~Hz}$ to $200 \mathrm{~Hz}$, was $120.8 \mathrm{~dB}$. After optimization, the vibration acceleration level of the middle supporting platform was 94.4 dB. The vibration acceleration level decreased by $26.4 \mathrm{~dB}$.

Figure 12 shows the frequency spectrum of the vibration acceleration of the middle supporting platform. Before optimization, the maximum vibration acceleration was $10.7 \times 10^{-4} \mathrm{~m} / \mathrm{s}^{2}$. After optimization, the maximum vibration 
acceleration was $3.99 \times 10^{-4} \mathrm{~m} / \mathrm{s}^{2}$. From Figure 12, the vibration acceleration was reduced across the frequency range after optimization.

\section{Conclusion}

To optimize the vibration reduction ability of ladder track, a new method, that is, the finite element method coupled with ant colony optimization, was proposed. We introduced how to build the FEM model and how to couple the FEM with ACO. The density of the sleeper pad and the elasticity modulus of the sleeper pad were optimized using this method. After optimization, the vibration acceleration level of the middle supporting platform was reduced from $102.8 \mathrm{~dB}$ to $94.4 \mathrm{~dB}$. The optimized density of the sleeper pad was $620 \mathrm{~kg} / \mathrm{m}^{3}$. The optimized elasticity modulus of the sleeper pad was $6.25 \times 10^{6} \mathrm{~N} / \mathrm{m}^{2}$.

\section{Conflict of Interests}

The authors declare that there is no conflict of interests with regard to this study and the publication of this paper.

\section{References}

[1] G. Kouroussis, D. Connolly, and O. Verlinden, "Railwayinduced ground vibrations-a review of vehicle effects," International Journal of Rail Transportation, vol. 2, no. 2, pp. 69-110, 2014.

[2] H. Wakui, N. Matsumoto, and H. Inoue, "Ladder sleeper and new track structures development," Quarterly Report of RTRI, vol. 37, no. 3, pp. 110-111, 1996.

[3] M. Oyado, N. Matsumoto, and H. Wakui, "Running performance on ballasted ladder track," RTRI Report, vol. 10, no. 9, pp. 51-56, 1996.

[4] R. J. Hosking and F. Milinazzo, "Floating ladder track response to a steadily moving load," Mathematical Methods in the Applied Sciences, vol. 30, no. 14, pp. 1823-1841, 2007.

[5] R. J. Hosking and F. Milinazzo, "Modelling the floating ladder track response to a moving load by an infinite bernoulli-euler beam on periodic flexible supports," East Asian Journal on Applied Mathematics, vol. 2, no. 4, pp. 285-308, 2012.

[6] C. K. Hui and C. F. Ng, "The effects of floating slab bending resonances on the vibration isolation of rail viaduct," Applied Acoustics, vol. 70, no. 6, pp. 830-844, 2009.

[7] H. Xia, Y. Deng, Y. Zou, G. de Roeck, and G. Degrande, "Dynamic analysis of rail transit elevated bridge with ladder track," Frontiers of Architecture and Civil Engineering in China, vol. 3, no. 1, pp. 2-8, 2009.

[8] H. Xia, Y. Deng, C. Xia, G. De Roeck, L. Qi, and L. Sun, "Dynamic analysis of coupled train-ladder track-elevated bridge system," Structural Engineering and Mechanics, vol. 47, no. 5, pp. 661-678, 2013.

[9] H. Xia, J. G. Chen, C. Y. Xia, H. Inoue, Y. Zenda, and L. Qi, "An experimental study of train-induced structural and environmental vibrations of a rail transit elevated bridge with ladder tracks," Proceedings of the Institution of Mechanical Engineers, Part F: Journal of Rail and Rapid Transit, vol. 224, no. 3, pp. 115-124, 2010.
[10] H. Inoue, Y. Zenda, L. Qi, and C. Y. Xia, "Dynamic experiment of an urban elevated bridge with ladder track under moving trains," in Proceedings of the 4th International Symposium on Environment Vibrations - Prediction, Monitoring, Mitigation and Evaluation, 2009.

[11] H. Jin, W. Liu, and Y. Fan, "Modal analysis of damping performances of the ladder track with different bearing styles," in Proceedings of the 2nd International Conference on Railway Engineering, 2012.

[12] H. Jin, W.-N. Liu, and W.-B. Wang, "Analysis of modal test of the ladder track," Engineering Mechanics, vol. 30, no. 3, pp. 459-463, 2013.

[13] Z. Yan, V. Markine, A. Gu, and Q. Liang, "Optimisation of the dynamic properties of ladder track to minimise the chance of rail corrugation," Proceedings of the Institution of Mechanical Engineers, Part F: Journal of Rail and Rapid Transit, vol. 228, no. 3, pp. 285-297, 2014.

[14] Z. Q. Yan, V. Markine, A. J. Gu, and Q. H. Liang, “Optimization of the dynamic properties of the ladder track system to control rail vibration using the multipoint approximation method," Journal of Vibration and Control, vol. 20, no. 13, pp. 1967-1984, 2014.

[15] A. Colorni, M. Dorigo, and V. Maniezzo, "Distributed optimization by ant colonies," in Proceedings of ECAL91-European Conference on Artificial Life, pp. 134-142, MIT Press, Cambridge, Mass, USA, 1992.

[16] J.-L. Deneubourg, S. Aron, S. Goss, and J. M. Pasteels, “The selforganizing exploratory pattern of the argentine ant," Journal of Insect Behavior, vol. 3, no. 2, pp. 159-168, 1990.

[17] S. Goss, S. Aron, J. L. Deneubourg, and J. M. Pasteels, "Selforganized shortcuts in the Argentine ant," Naturwissenschaften, vol. 76, no. 12, pp. 579-581, 1989.

[18] S. E. V. V. Key and T. C. Baker, "Observations on the trail deposition and recruitment behaviors of the argentine ant, Iridomyrmex humilis (Hymenoptera: Formicidae)," Annals of the Entomological Society of America, vol. 79, no. 2, pp. 283-288, 1986.

[19] C. Blum, "Ant colony optimization: introduction and recent trends," Physics of Life Reviews, vol. 2, no. 4, pp. 353-373, 2005.

[20] B. C. Mohan and R. Baskaran, "A survey: ant colony optimization based recent research and implementation on several engineering domain," Expert Systems with Applications, vol. 39, no. 4, pp. 4618-4627, 2012.

[21] F. A. C. Viana, G. I. Kotinda, D. A. Rade, and V. Steffen Jr., "Tuning dynamic vibration absorbers by using ant colony optimization," Computers and Structures, vol. 86, no. 13-14, pp. 1539-1549, 2008.

[22] Y. Chen, "Ant colony system for continuous function optimization," Journal of Sichuan University (Engineering Science Edition), vol. 36, no. 6, pp. 117-120, 2004. 

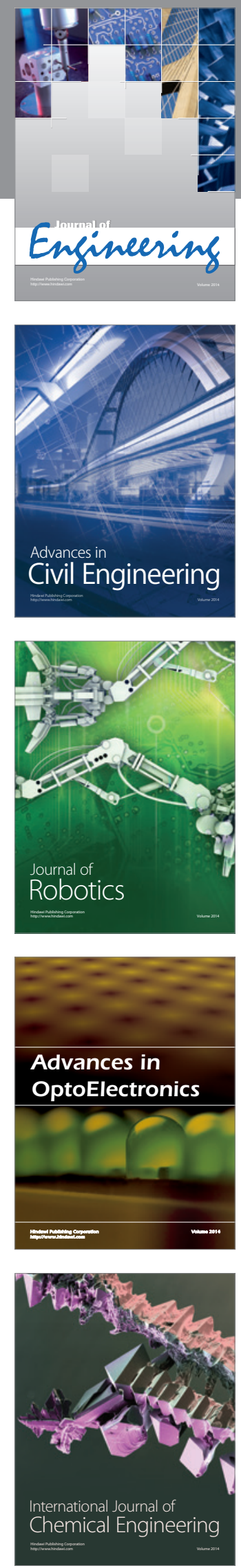

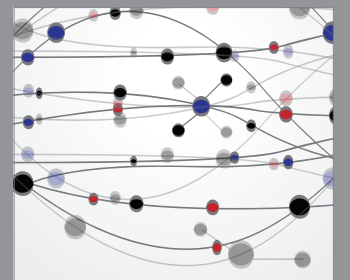

The Scientific World Journal
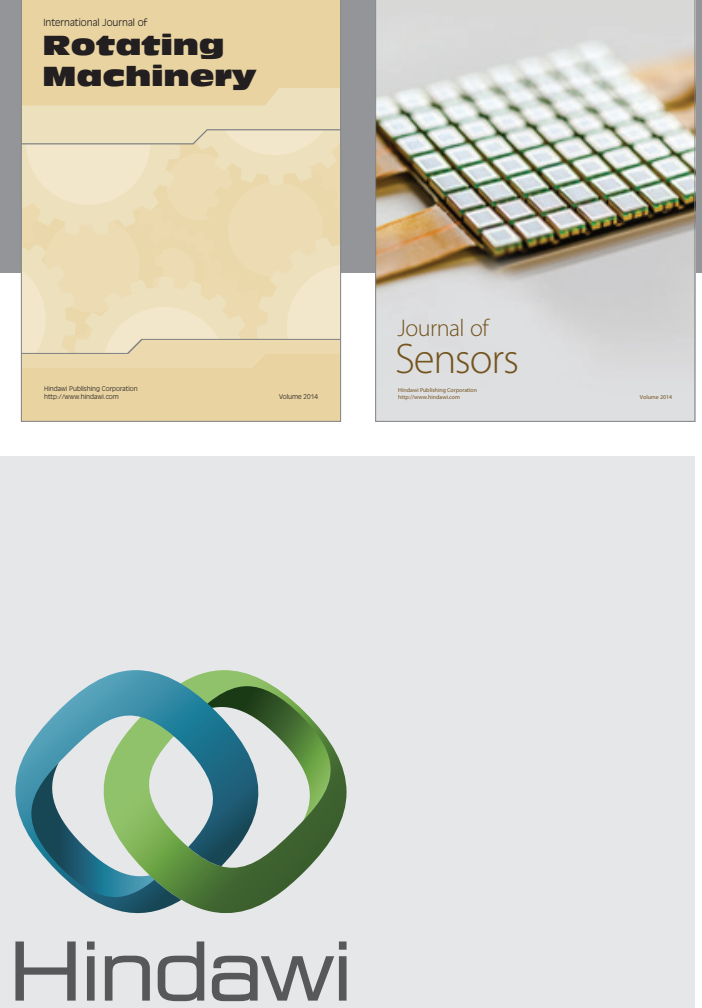

Submit your manuscripts at http://www.hindawi.com
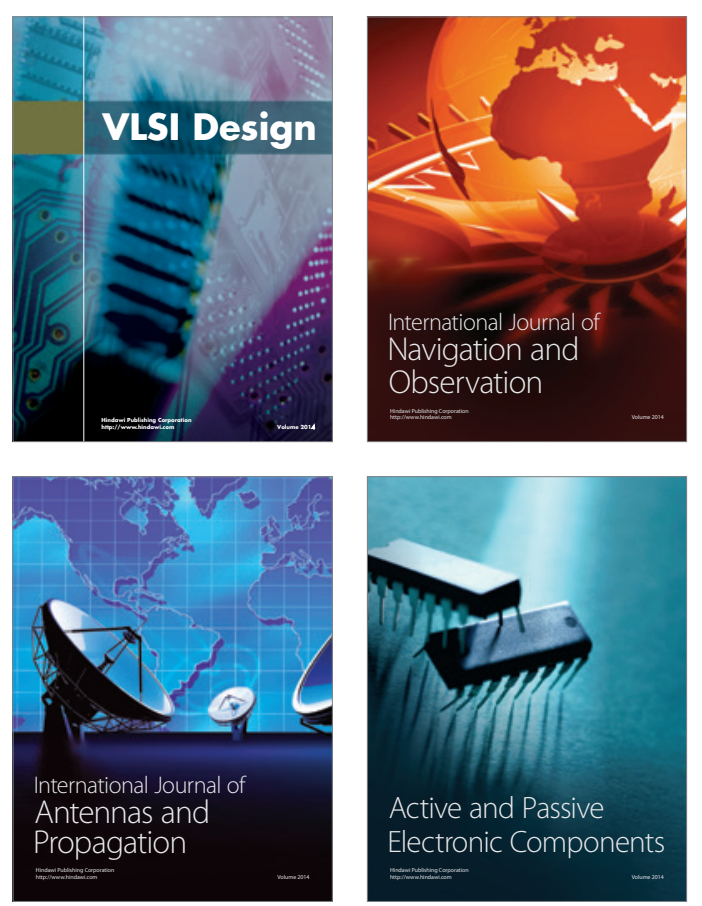
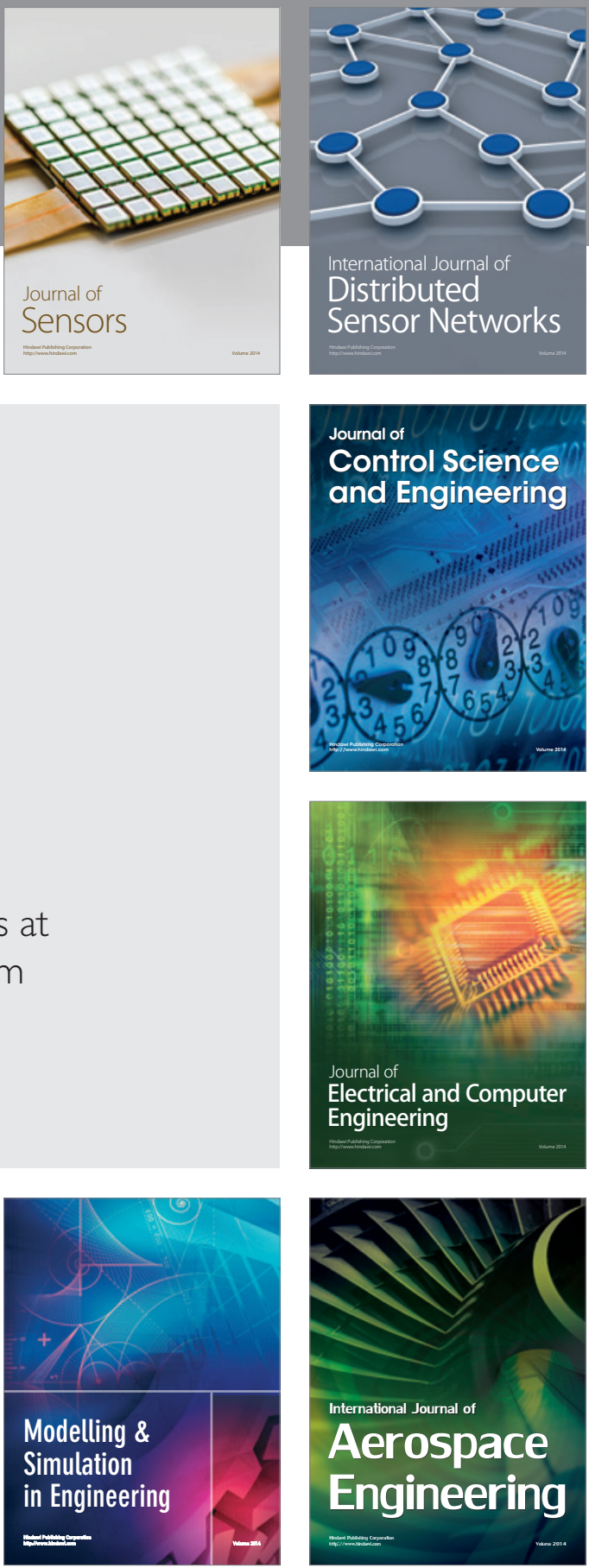

Journal of

Control Science

and Engineering
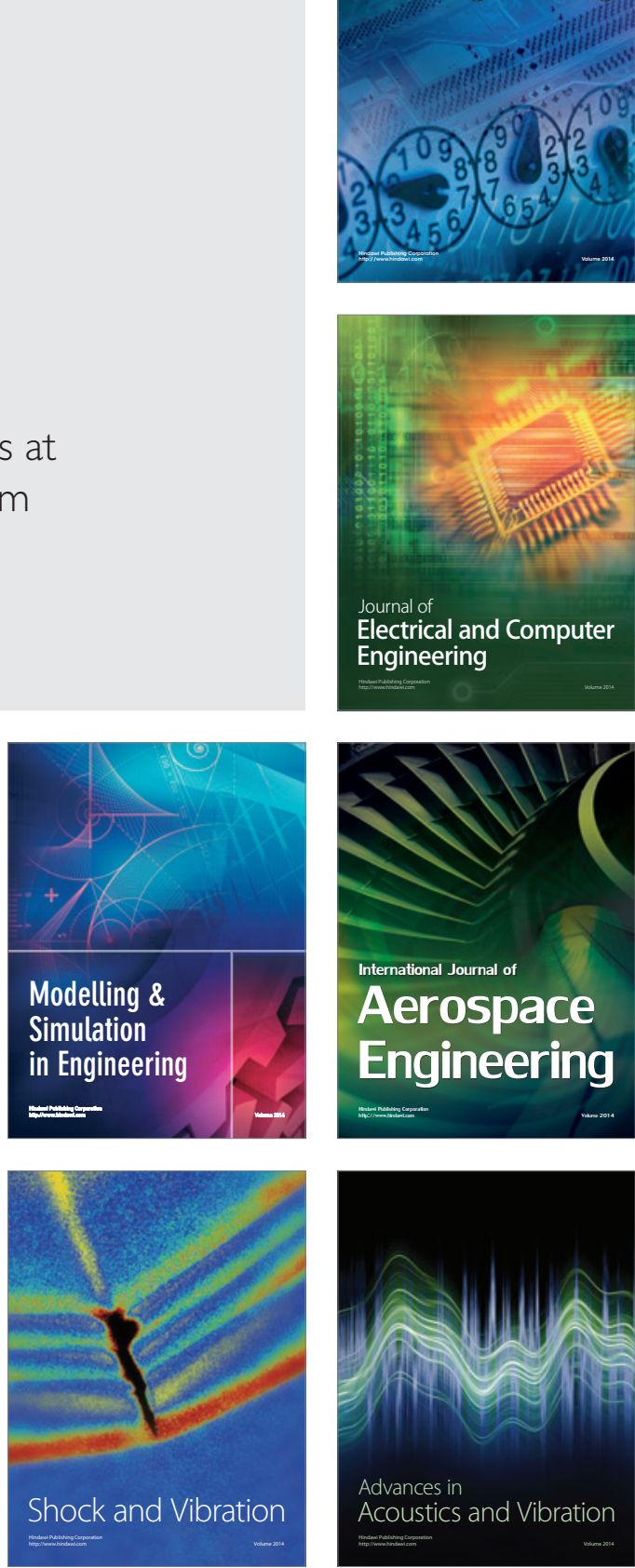